\title{
ORIENTAÇÃO DIRIGIDA AO PACIENTE SUBMETIDO AO TRANSPLANTE DE FÍGADO: PAPEL RELEVANTE DO ENFERMEIRO
}

\author{
Guidance driven to patient submitted to liver transplantation: the important role of the nurse.
}

\author{
Karina Dal Sasso ${ }^{1}$, Cristina Maria Galvão ${ }^{2}$
}

\section{RESUMO}

O objetivo do presente estudo é tecer considerações teóricas relacionadas ao ensino na alta hospitalar do paciente submetido ao transplante de fígado. Sendo o transplante de fígado um procedimento cirúrgico de alta complexidade, nota-se a importância do papel do enfermeiro no ensino como facilitador desse processo. Entretanto, só será efetivo se for adequado às necessidades do paciente e de sua família e se promover a adesão do mesmo ao tratamento e ao seguimento clínico, resultando no sucesso do próprio transplante.

Descritores: enfermagem, transplante de fígado, alta do paciente, papel do profissional de enfermagem, ensino, educação.

Trabalho realizado na Escola de Enfermagem de Ribeirão Preto da Universidade de São Paulo/Centro Colaborador da OMS para o desenvolvimento da pesquisa em enfermagem.

1. Enfermeira Especialista em Laboratório e Mestre pelo Programa de Pós-Graduação do Departamento de Enfermagem Geral e Especializada da Escola de Enfermagem de Ribeirão Preto da Universidade de São Paulo;

2. Enfermeira, Professor Associado do Departamento de Enfermagem Geral e Especializada da Escola de Enfermagem de Ribeirão Preto da Universidade de São Paulo.

Endereço para correspondência: Karina Dal Sasso - Avenida Bandeirantes, 3900 - Monte Alegre - CEP 14040-902 - Ribeirão Preto - SP - Fone: (16) 36023467 - Fone/Fax: (16) 36108543 - E-mail: dalsasso@eerp.usp.br

Recebido em: 30/06/05

Aceito em: 11/07/05

\section{INTRODUÇÃO}

O transplante de fígado é a única opção de tratamento viável para pacientes portadores de falência hepática irreversível, até o momento. Sendo um procedimento cirúrgico de alta complexidade, o paciente ao vivenciar o transplante, necessita adaptar-se ao longo de todo o processo cirúrgico à nova condição de vida, livre da doença..$^{1-3}$

O papel do enfermeiro, como facilitador desse processo, inclui o ensino como um dos métodos para proporcionar o sucesso da cirurgia. Ensinar um paciente significa fornecer atividades educativas direcionadas para as necessidades destes, incluindo os aspectos da terapêutica, educação e promoção da saúde. ${ }^{4}$

O objetivo do presente estudo é tecer algumas considerações teóricas relacionadas ao ensino na alta hospitalar do paciente submetido ao transplante de fígado.

\section{O ENSINO NA ALTA HOSPITALAR}

$O$ ensino é uma ação educativa do enfermeiro com o paciente, a fim de desenvolver atitudes e estratégias frente à sua condição de saúde. É o meio pelo qual o paciente pode adquirir conhecimentos e habilidades, ser encorajado a participar do seu tratamento, tomando decisões e assumindo responsabilidades. É considerado parte integrante do cuidado de enfermagem, uma vez que este profissional diariamente se confronta com as informações que os pacientes necessitam. ${ }^{5-7}$

Em especial, quando se trata do transplante de fígado, o ensino é uma condição sine qua non para a sobrevida do paciente que, no momento de sua alta, deverá priorizar seu próprio cuidado para manter sua condição de vida. Sendo assim, o paciente, desde sua inclusão no cadastro técnico, é preparado para enfrentar o processo cirúrgico e a alta hospitalar. Neste momento recebe orientação verbal e escrita do enfermeiro, por meio de um manual que contém informações de todo o período perioperatório. 
No manual ilustrativo e educativo constam: (1) definição e histórico do transplante, (2) as principais funções do fígado, (3) causas da doença hepática e suas complicações, (4) indicações e contraindicações ao transplante, (5) funcionamento da lista de espera, (6) aspectos relativos ao doador, (7) convocação do receptor para a realização da cirurgia, (8) tópicos importantes da cirurgia e da técnica cirúrgica, (9) informações relativas ao Centro de Terapia Intensiva e à Unidade de Internação, (10) complicações comuns do transplante de fígado (infecções, rejeição e outras complicações), terminando com (11) descrição das principais medicações usadas (ciclosporina, tacrolimus e corticóides, entre outros), (12) exames complementares após o transplante (biopsia hepática, ultrasonografia, tomografia computadorizada, arteriografia hepática, colangiografia e endoscopia digestiva alta) e (13) orientações para alta hospitalar.

$\mathrm{Na}$ alta hospitalar, o enfermeiro pode utilizar diversas estratégias, dentre elas, a informação verbal individualizada para o paciente e a família ou cuidador, destacando assim, a importância de uma interação interpessoal eficiente e o uso de meios de comunicação não-verbais. Além disso, faz-se necessária a entrega de informações por escrito, como complemento do processo de ensino-aprendizagem., ${ }^{1,5}, 6$

Pode-se também, solicitar a colaboração de um paciente transplantado há mais tempo para encorajar o enfrentamento da nova realidade, integrar a participação de outros membros da equipe (assistente social, nutricionista, psicólogo, médico) e esclarecer as dúvidas e angústias numa linguagem compatível com o discernimento do paciente. , $^{2,3}$

O paciente deverá ser capaz de manter uma dieta adequada ao seu estado nutricional, monitorar peso, pressão arterial e glicemia, conhecer os medicamentos prescritos, bem como a dosagem e posologia, reconhecer sinais e sintomas de rejeição, de infecções ou outras complicações, aderir à terapêutica médica (coleta de exames, consultas), além de evitar o contato com pessoas doentes, usar máscara e realizar a lavagem das mãos com freqüência. $\mathrm{O}$ paciente é ensinado a procurar a equipe médica sempre que houver intercorrências que venham a interferir no resultado do transplante ${ }^{1,3,8}$.

O enfermeiro deverá questionar, clarificar e atuar em alguns pontos importantes para o paciente transplantado no momento da alta hospitalar, dentre eles ${ }^{1}$.

- Hábitos de vida diária: higiene corporal e bucal;

- Hábitos nocivos: ingestão de bebidas alcoólicas e outras drogas;

- Tratamento farmacológico: identificação dos fármacos imunossupressores, normas para sua correta administração e efeitos adversos;

- Medidas de prevenção: identificação de vacinas recomendadas e utilização de protetores solares diariamente;

- Exercício físico: suave ou moderado, conforme liberação médica;

- Situações de alarme: identificação e comunicação com a equipe médica em situações de risco.

O plano de cuidados de enfermagem ao paciente transplantado de fígado deve integrar não somente o processo patológico, como também medidas de prevenção, considerando as necessidades do paciente e de sua família, utilizando o ensino como uma ferramenta para facilitar os conhecimentos necessários que garantam a sua independência no domicílio e permitam a detecção precoce das complicações relacionadas ao procedimento cirúrgico. ${ }^{1-3}$

\section{CONSIDERAÇÕES FINAIS}

O transplante de fígado proporciona uma nova concepção de vida para o paciente, que antes vivia no risco iminente de morte devido às complicações da doença de base e à longa espera pelo órgão. O papel do enfermeiro no ensino é fundamental no período perioperatório. Entretanto, só será efetivo se for adequado às necessidades do paciente e de sua família e se promover a adesão do mesmo ao tratamento e ao seguimento clínico, resultando no sucesso do próprio transplante.

\section{ABSTRACT}

The aim of the present study is to develop theoretical considerations on the education of patients submitted to liver transplantation upon their discharge from the hospital. Due to the fact that the liver transplantation consists in a highly complex surgical procedure, the relevant role performed by nurses as an educator facilitating such process is noticeable. However, it will only be effective if suitable to the patient and family's needs and if promoting the patient's adherence to the treatment and clinical follow-up, thus resulting in a successful outcome of the whole transplantation.

Key words: nursing, liver transplantation, patient discharge, nurse's role, teaching, education.

\section{REFERÊNCIAS}

1. Cerezo MCM, Simón CS, Muñoz MP, Romanillos MTA, Agustí IT, Canales PB. Estudio del proceso educativo en el paciente con trasplante hepático. Enferm. Intensiva 2001;12(2):58-65.

2. Sasso KD, Azevedo MAJ. Assistência de enfermagem no transplante de fígado: a importância do enfermeiro nessa modalidade terapêutica. Rev Nursing 2003;60(6):16-20.

3. Duarte MMF, Salviano MEM, Gresta MM. Assistência de enfermagem em transplantes. In: Pereira WA. Manual de transplantes de órgãos e tecidos. Rio de Janeiro: Medsi; 2000. p. 459-83.

4. Deccache A, Isabelle A. An European perspective: common developments, differences and challenges in patient education. Patiente Educ Couns 2001(44):7-14

5. Johansson K, Leino-Kilpi H, Salanterä S, Lehtikunnas T, Ahonen P, Elomaa L, et al. Need for change in patient education: a finnish survey from the patient's perspective. Patient Education and Counseling 2003;51(3):239-45.

6. Zago MMF. Considerações sobre o ensino do paciente cirúrgico. Rev Esc Enfermagem USP 1993;27(1):67-71.

7. Zago MMF, Casagrande LDR. A comunicação do enfermeiro cirúrgico na orientação do paciente: a influência cultural. Rev Lat Am Enfermagem 1997;5(4):69-74.

8. Cowling T, Jennings LW, Goldstein RM, Sanchez EQ, Chinnakotla S, Klintmalm $\mathrm{GB}$, et al. Societal reintegration after liver transplantation: findings in alcohol-related and non-alcohol-related transplant recipients. Ann Surg 2004;239(1):93-8 